\title{
Why We Need a Trading System for Childbearing Quota?
}

\author{
Hualei Yang ${ }^{1}$,Zheng Shen ${ }^{2 *}$ and Wenchao Zhang ${ }^{1}$ \\ ${ }^{1}$ School of Public Administration, Zhongnan University of Economics \& Law, China \\ ${ }^{2}$ School of Economics and Management, Zhejiang A\&F University, China
}

*Corresponding author: Zheng Shen, School of Economics and Management, Zhejiang A\&F University, Hangzhou, China.

To Cite This Article: Zheng Shen.Why We Need a Trading System for Childbearing Quota?. Am J Biomed Sci \& Res. 2019 - 6(2). AJBSR.MS.ID.001018. DOI: 10.34297/AJBSR.2019.06.001018.

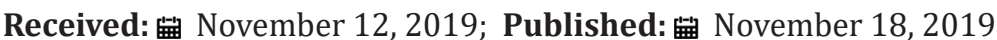

\section{Opinion}

On one side of the world, many countries in Sub-Saharan Africa, Latin America, and South Asia have not escaped from the "Malthusian Trap" yet [1]. Since agricultural production still plays a dominant role and the process of industrialization and urbanization continues to be slow, these areas appear to be a low level of economic development and personal income. Without restriction on fertility, these areas have high fertility rate and face excess population, causing population growth ahead of economic growth. The imbalance between resources and population lead most people to live below the poverty line. This is particularly true in Africa, where the total fertility rate (TFR) 6.0 and, in 2010, there were more than 400 million people falling into poverty, accounting for approximately half of Africa's total population and $1 / 3$ of the number of poor people in the world. Rapid population growth has serious consequences, such as inequities in income distribution, unemployment problems, shortage of food and water supply, limited access to healthcare and education.

On the other side of the world, countries in Europe, North America and parts of East Asia have completed the process of industrialization and urbanization, with a high level of economic development and personal income. However, these areas also stepped into "low fertility trap", with a low TFR being lower than the replacement level fertility in recent decades [2]. Meanwhile, developed countries like Japan and German are encountering the challenges of rapid population aging, such as lack of working-age populations and considerable strain on public finances for pension and health insurance.

Given economic disparity among regions and countries, individual's fertility behaviours play different roles in affecting social well-being. For low and middle-income countries (LMIC), the excess of births will create a negative externality problem because high fertility rates lead to a series of environmental and social concerns. For high-income countries, since labour force shortage and population aging, having more children may have potentially positive externality for the benefit of work force and sustainability of social security system. In the presence of externalities, the final allocation of economic resources should not be the Pareto optimality [3]. A common way to avoid the misallocations of resources is to implement a market-based policy aiming on the correction of marketing failures. This has been widely applied into the environmental issues, for instance, the transfer of carbonemitting quotas, known as the cap-and-trade program (CTP). In the fact that LMIC have long been experiencing high fertility rates associated with negative externalities, it is necessary to develop an integrated system of CTP allowing proper management of human population growth. The CTP system for childbearing quota should work as follows: First, the government determines an overall quota of childbearing, for instance, each family has rights to give birth to two babies. Second, the government issues the childbearing vouchers that permit family to have more than two children and distribute such permits through auction market. Third, government needs to set up a trading platform that allows these childbearing permits to be traded among various families with different demand for children. Of course, one major concern is that the CTP on childbearing might give rise to the problems of illegal surrogacy and human trafficking. Therefore, complementary laws and regulations are vital to establish so as to prevent the possible detrimental effect.

\section{Funding}

This research was funded by the National Natural Science Foundation of China (Grant number:71903177). 


\section{References}

1. Korotayev A, Zinkina J (2015) East Africa in the Malthusian Trap? Journal of Developing Societies 31(3): 385-420.

2. Lutz W, Skirbekk V, Testa M R (2006) The Low-Fertility Trap Hypothesis:
Forces that May Lead to Further Postponement and Fewer Births in Europe. Vienna Yearbook of Population Research 4: 167-192.

3. Coase R H (1960) The Problem of Social Cost. Journal of Law \& Economics $3: 1-44$ 